R. Attou
P. Reper

\title{
Slow-release clomipramine acute poisoning with radio-opaque gastric bezoar
}

Received: 29 March 2013

Accepted: 5 April 2013

Published online: 26 April 2013

(C) Springer-Verlag Berlin Heidelberg and ESICM 2013

R. Attou · P. Reper ( $)$

Critical Care Department, University Hospital Brugmann,

Free University Brussels, Brussels, Belgium

e-mail: prmddr@gmail.com

A 48-year-old woman with depression was intubated on admission to the intensive care unit for deep coma of unknown origin. Post-intubation chest X-ray showed the intragastric presence of a radio-opaque pharmacobezoar with 22 tablets (Fig. 1). Toxicology screening results and information from the family confirmed a witnessed intake of a slow-release preparation of clomipramine (AnafranilRetard $75 \mathrm{mg}$, depot tablets) $12 \mathrm{~h}$ before admission.

Slow-release clomipramine is known to produce a radio-opaque pharmacobezoar that can be removed by gastroscopic examination $[1,2]$. This observation

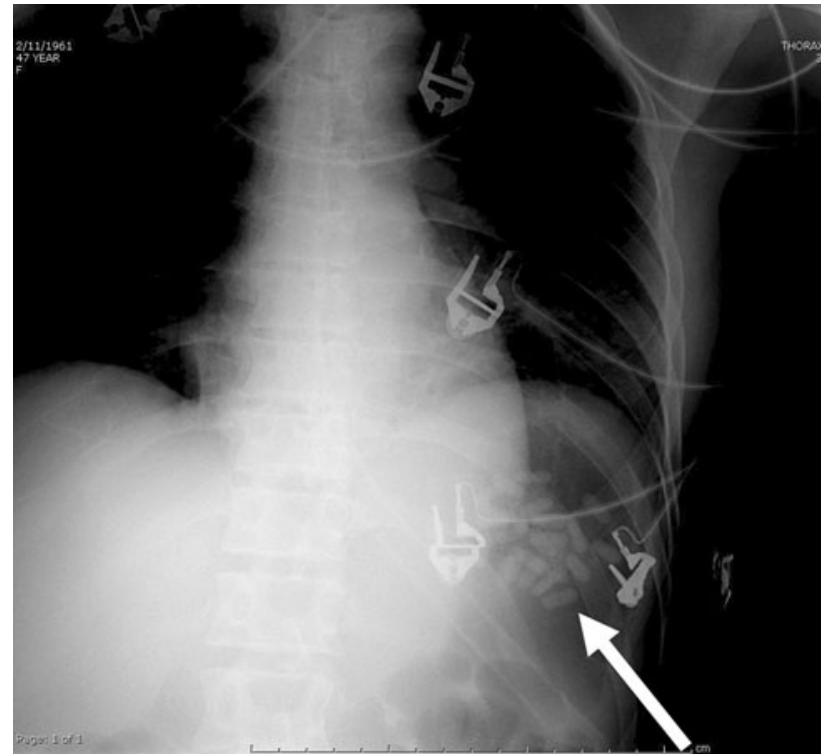

Fig. 1 Radio-opaque gastric pharmacobezoar with 22 tablets (see arrow) on post-intubation chest X-ray

confirms that chest X-ray can disclose the cause of a coma related to severe intoxication.

\section{References}

1. Lapostolle F, Finot MA, Adnet F, Borron SW, Baud FJ, Bismuth C (2000)

Radiopacity of clomipramine conglomerations and unsuccessful endoscopy: report of 4 cases. J Toxicol Clin Toxicol 38:477-482
2. Höjer J, Personne M (2008) Endoscopic removal of slow release clomipramine bezoars in two cases of acute poisoning. Clin Toxicol (Phila) 46(4):317-319 